\title{
Consideraciones etnográficas sobre la crianza entre mujeres de Senegal y de Gambia en instituciones de atención a la violencia de género en Cataluña
}

Ethnographic considerations on the upbringing of women from Senegal and Gambia in institutions for dealing with male violence against women in Catalonia

Lourdes García Tugas

Profesora Colaboradora, Universitat Oberta de Catalunya (Barcelona, España)

mgarciatu@uoc.edu

\section{Beatriz García García}

Profesora Lectora, Universitat Oberta de Catalunya (Barcelona, España)

bgarciagarcia1@uoc.edu

\section{Jorge Grau Rebollo}

Departamento de Antropología Social y Cultural. Universidad Autónoma de Barcelona. jordi.grau@uab.es

\section{CRIANZA EN CONTEXTOS DE VULNERABILIDAD SOCIOCULTURAL MONOGRÁFICO COORDINADO POR JORGE GRAU REBOLLO}

\section{RESUMEN}

Las causas de institucionalización de niños, niñas y adolescentes en Cataluña son diversas y abarcan desde procesos migratorios en solitario hasta desamparos administrativos por situaciones de riesgo que requieren una actuación inmediata de protección. Pero, más allá de la violencia ejercida sobre ellos/as, su condición de víctimas (in)directas en casos de violencia machista en el hogar puede pasar más desapercibida en estos contextos inestables de crianza vulnerable. En este artículo nos centraremos en la situación de hijos/as de personas inmigradas, que acuden con sus madres a centros residenciales de atención y recuperación de la violencia machista. Para ello, examinamos las características de este servicio en relación con la diversidad cultural y con la adecuación de distintas pautas culturales para valorar las necesidades específicas de crianza. Nuestro análisis permite presentar propuestas de intervención orientadas a profesionales que gestionan procesos de protección.

\section{ABSTRACT}

The causes of the institutionalization of children and teenagers in Catalonia are diverse. They range from migratory processes on their own to administrative abandonment due to situations of risk that require immediate protective action. However, beyond the violence exercised on them, their condition as (in)direct victims in domestic violence cases may go unnoticed in these unstable contexts of vulnerable upbringing. This article will focus on children of immigrants who attend residential centers for care and recovery from domestic violence with their mothers. To do so, we examine this service's characteristics concerning cultural diversity and the adequacy of different cultural patterns to assess specific parenting needs. Our analysis allows us to present some intervention proposals oriented to professionals who manage these protection processes.

PALABRAS CLAVE

entornos institucionales de protección | violencia machista | crianza | menores senegambianos KEYWORDS

institutional protective environments | male violence | childrearing | senegambian minors

\section{Introducción}

En Cataluña se dispone de una red de recursos residenciales de urgencia, de recuperación y acogimiento, y de autonomía para la atención a las mujeres víctimas de violencia machista. Se trata de servicios confidenciales de protección (y por ello en este artículo no incluiremos datos identificativos de las mujeres a las que nos referimos ni de sus hijas e hijos, y emplearemos pseudónimos para referirnos a ellos/as). Los recursos residenciales orientados a la atención de la violencia machista tienen un doble objetivo: proteger a las mujeres y a sus hijas/os y ayudar a la recuperación de los efectos adversos de las violencias machistas (especialmente la violencia de género en el ámbito de la pareja).

A pesar de que las mujeres de nacionalidad senegalesa o gambiana no constituyen el colectivo más numeroso entre las mujeres extranjeras atendidas en estos servicios en Cataluña, sí presentan ciertos 
rasgos genéricos que pueden dificultar la intervención de las profesionales y el funcionamiento habitual de los recursos residenciales especializados en violencias machistas. Como ha puesto de relieve el trabajo de campo, este problema viene en buena parte inducido por el desconocimiento que tienen estos profesionales acerca de las pautas culturales sobre la crianza, agravado por la imposibilidad de mantener una comunicación fluida en alguno de los idiomas autóctonos de las mujeres.

En este artículo presentamos algunos resultados de nuestros trabajos de campo en una casa de acogida con mujeres de nacionalidad senegalesa y gambiana en Cataluña y en los entornos familiares de estas mujeres en Senegal y Gambia (1). Nos centramos para ello en ciertas características culturales de la crianza en este colectivo, así como en otros aspectos relacionales y de dinámica cotidiana que inciden en esta. Buscamos con ello contribuir a la compresión sobre las formas culturales de pensar, sentir y actuar de las mujeres atendidas, para facilitar una atención posterior mejor adaptada y más sensible culturalmente en un colectivo que presenta diversos factores confluentes de vulnerabilidad (mujeres migrantes, extranjeras de países empobrecidos, racializadas y víctimas de violencia de género).

El objetivo central del texto es analizar si, a través de la acción socioeducativa de un recurso asistencial y de la gestión de las actuaciones derivadas que se dirigen particularmente a mujeres de Senegal y Gambia, se puede estar involuntariamente agravando su condición vulnerable. Para tratar de dar respuesta a esta cuestión, trataremos en primer lugar de contextualizar el fenómeno de las mujeres senegalesas y gambianas que acuden a la red de atención a las víctimas de violencia machista en Cataluña. En segundo lugar, identificaremos los factores de vulnerabilidad a las que están sujetas estas mujeres. Seguidamente, aportaremos datos etnográficos sobre pautas y prácticas culturales en origen que permitan comprender algunas dinámicas que pueden replicarse en sus entornos institucionalizados $y$, por último, esbozaremos algunas conclusiones que sirvan como base para intervenciones futuras que tengan en cuenta la perspectiva intercultural en las situaciones abordadas.

Los resultados de este trabajo pueden ser útiles tanto para profesionales de los servicios de atención a las víctimas de violencia machista, como para otros/as sectores que intervienen con este colectivo (por ejemplo, de los ámbitos sociosanitario o educativo) para prevenir que el desconocimiento de dichas pautas culturales coloque a la mujer y a sus hijas e hijos en una situación de, todavía, mayor vulnerabilidad.

\section{Metodología: técnicas de investigación, muestra y limitaciones}

Nuestro trabajo se basa en una investigación cualitativa que, a través de la etnografía, explora las prácticas culturales en origen junto con la práctica profesional en un centro de acogida en Cataluña (por razones de confidencialidad y de protección de las mujeres, no es posible precisar el ámbito comarcal ni proporcionar más detalles sobre el centro que pudiesen facilitar su identificación). Combinamos para ello: a) información procedente de fuentes bibliográficas relevantes para el ámbito abordado; b) datos extraídos de expedientes de mujeres de Senegal y Gambia víctimas de violencia machista atendidas en uno de los servicios residenciales; y c) investigación etnográfica tanto en destino (observación y entrevistas a mujeres en el centro y entrevistas a personal experto en estas intervenciones), como en origen (observaciones y entrevistas a familias y personas encargadas del cuidado de menores).

En Cataluña, el trabajo de campo en la casa de acogida se ha nutrido de la observación participante y de la experiencia profesional de Lourdes García a lo largo de cinco años. La convivencia ininterrumpida con las mujeres y sus hijos e hijas proporciona datos e información relevantes para la investigación ya que permite observar dinámicas cotidianas de crianza, hablar prolongadamente con las madres y obtener el punto de vista de los equipos de intervención que trabajan en la casa sobre la base de una interacción diaria.

En Senegal, se ha podido llevar a cabo un trabajo de campo de dos años por parte de Beatriz García. Para el tema concreto de este artículo se han realizado además 3 entrevistas en profundidad a familias, una entrevista al encargado de una escuela coránica y otra a una encargada de un orfanato católico, todos ellos al cuidado de menores. Sus relatos aportan información relevante sobre concepciones folk sobre la crianza en esa zona. Las entrevistas a familias se hicieron a mujeres insertas en núcleos familiares compuestos por una horquilla de 7 a 11 integrantes, que viven en un entorno urbano. En todas las casas había miembros de diferentes generaciones y menores de corta edad que precisaban cuidados. Dos de las familias tenían vínculos con la migración, con miembros viviendo en el extranjero y 
en la casa se cuidaba de su descendencia. El trabajo conjunto con un tercer investigador, Jorge Grau, ha permitido un análisis más integrado sobre los factores que convendría tener presentes en el diseño de actuaciones profesionales en este ámbito.

En la recogida y análisis de datos hemos tenido especialmente en cuenta la perspectiva de género y las construcciones socioculturales folk sobre maternidad que rigen la crianza de estas mujeres y que, como veremos, a menudo colisionan con las pautas de crianza consideradas como adecuadas en las prácticas profesionales de intervención. Además, hemos tenido en cuenta, como sugiere Spindler (1993), el énfasis que las madres ponen en ciertos valores transmitidos durante la enculturación de sus hijos y la influencia que demuestran tener sobre la forma de sentir y actuar en el marco sociocultural en que se desenvuelven.

Pese a la ventaja de poder llevar a cabo un trabajo de campo simultáneo en origen y en destino, hemos tratado de dar voz a las propias mujeres en Cataluña. Sin embargo, hemos topado con diversas dificultades al respecto: a) algunas de ellas ya no se encontraban en el servicio en el momento de iniciarse la investigación, por lo que debemos basarnos en informes elaborados sobre estos casos; b) es complejo explorar etnográficamente un servicio de alta complejidad como una casa de acogida y, simultáneamente, formar parte de su funcionamiento (una de las etnógrafas es trabajadora en el centro); c) en Senegal, por diferentes razones, el trabajo de campo ha debido limitarse a las zonas de Dakar y alrededores (Thies), no pudiendo abarcar otras zonas de interés para la investigación; y d) hemos topado con la dificultad añadida de la pandemia en ambos contextos, que ha impedido realizar entrevistas programadas con mujeres y con otras/os profesionales y recursos.

\section{La crianza en entornos institucionales de protección: mujeres senegambianas en Cataluña}

\subsection{Género, migración y violencia}

En España, en el año 2020 se contabilizaron 29.215 mujeres víctimas de violencia de género, de las cuales el 37\% habían nacido en el extranjero (INE 2021). De estas, el 19\% eran de origen africano, aunque se necesitan datos más precisos en lo referente a nacionalidad ( $\mathrm{y}$ también respecto al origen del agresor). Además, al tratarse de datos correspondientes a asuntos para los que han dictado medidas cautelares $u$ órdenes de protección, representan solo una parte del total de las situaciones de abuso en el conjunto del país. A nivel autonómico, Cataluña registra el $9,7 \%$ de mujeres víctimas de violencia de género en España en ese año, solo superada por Andalucía (23,3\%), la Comunidad Valenciana $(15,3 \%)$ y la Comunidad de Madrid (10,8\%).

La Organización de Naciones Unidas define la violencia de género como "[el conjunto de] actos dañinos dirigidos contra una persona o un grupo de personas debido a su género y tiene su origen en la desigualdad de género, el abuso de poder y la existencia de normas dañinas" (ONU Mujeres 2021). De este modo, la violencia contra las mujeres se perfila como un ejercicio selectivo de abuso de poder hacia una determinada persona con quien se mantiene una relación jerárquica (real o simbólica) y se ejerce mediante coacciones físicas, psicológicas, políticas o materiales (Plaza Aleu 2012: 40). En último término, no deja de ser una violencia basada en la desigualdad entre mujeres y hombres, incrustada en marcos culturalmente específicos de poder y sumisión (Alberdi y Matas 2002) que, en el caso de mujeres inmigrantes africanas arrastra el peso de los imaginarios sobre su pasado colonial (Aixelà 2020).

En este sentido, a menudo estos marcos estructurales de desigualdad en destino no son ajenos a la construcciones androcéntricas de las relaciones de género en origen, como muestra Aixelà (2013) en el caso de las mujeres de Guinea Ecuatorial emigradas a España, donde los prejuicios y las actitudes racistas y xenófobas en destino dificultan aun más, si cabe, su integración social en España y pueden condicionar también los procesos de denuncia por maltrato y violencia, así como los recursos de afrontamiento de que puedan disponer para superarlos. Estas actitudes y prejuicios pueden verse agravados por cuestiones religiosas, de modo que la construcción social de la mujer musulmana que se ha hecho en Europa refuerza el imaginario de la subordinación femenina, alentando su invisibilidad social y la percepción victimista del problema (Aixelà 2006).

Pese a la reiterada constatación de la escasez de estudios que conecten movimientos migratorios, violencia contra las mujeres y modelos culturales de género en origen y en destino, diversas investigaciones han explorado esta conexión, especialmente encuadrando el caso de mujeres que llegan 
a sus países de destino mediante procesos migratorios no regularizados. Así, Jiménez-Lasserrotte y otros (2020) analizan recientemente el caso de mujeres que llegan en pateras a las costas españolas, frecuentemente tras un periplo vital que encierra diversos episodios de abusos, violaciones e incluso trata de blancas.

En un contexto similar, Rodríguez-Martínez y Cuenca-Piqueras (2019) recogen la percepción que las propias mujeres migrantes irregulares tienen sobre la naturaleza de la violencia que se ejerce contra ellas en casos de acoso sexual. Entre las conclusiones del estudio, destaca el impacto diferencial que este tipo de violencia tiene a largo plazo cuando proviene directamente de sus parejas afectivas. La intensidad que confiere el vínculo emocional con la pareja actúa como un multiplicador exponencial de la percepción de dolor y humillación causada por este tipo de abuso. Otros estudios, como los de Garnweidner-Holme y otros (2017) en Noruega, encaran la violencia sobre mujeres migrantes por parte de sus parejas como un problema de salud pública, sobre todo en ciertos periodos de la vida (como los embarazos), pese a la escasez de estudios al respecto. Estas consideraciones sanitarias se extienden también a la práctica de la mutilación genital femenina (Jiménez y otros 2016), incluyendo específicamente a mujeres provenientes de Senegal y de Gambia inmigradas en Cataluña (Sandu 2013).

Sin embargo, lejos de convertirse solo en víctimas pasivas, Sandu (2013) muestra cómo el apoyo mutuo entre las mujeres promueve formas de solidaridad (sisterhood solidarity) que tratan de combatir las desigualdades de género, étnicas y económicas (además de los estereotipos patriarcales) que las mujeres migrantes deben afrontar en la sociedad de destino. Un sentimiento de hermandad que ya autoras como Mercedes Jabardo (2006) o Codou Bop (2010) subrayaban como un factor esencial entre las mujeres africanas tanto en sus países de origen como en los contextos de migración.

Así, Jabardo y Ródenas (2017) subrayan la importancia de las dinámicas de construcción del espacio femenino y de su traslación a contextos de migración y diáspora, destacando las lógicas de ayuda y competencia, sobre todo en uniones polígamas. En este marco, sostienen lo siguiente:

"la poligamia en tanto que institución sitúa a las mujeres en posiciones diferentes: de vulnerabilidad en el marco de las relaciones conyugales, de competitividad en el espacio doméstico y de solidaridad/competitividad en el espacio femenino. $Y$ nos permite mostrar la capacidad de las mujeres para crear sus propias redes - y la manera asombrosa en la que cuidan e invierten en las mismas - tanto como reflejo de la posición desigual donde el sistema las coloca cuanto estrategia/fuente de poder para subvertir (o no) su posición en tanto que miembr(a) de un grupo subyugado" (Jabardo y Ródenas 2017: 376).

La importancia de las mujeres en el proceso migratorio va pareja a la relevancia del matrimonio, un símbolo de prestigio en las sociedades africanas tradicionales. Como Jabardo (2006: 106) señala: "La llegada de las mujeres estuvo, por tanto, muy vinculada a la proyección social de los hombres" (2). Este marco conyugal llega a justificar acciones de violencia extrema de los maridos senegaleses hacia sus esposas por asuntos relativos a su apariencia física o a su forma de cocinar (Bop 2010), y que tienen como denominador común la concepción de la mujer como menor de edad que debe ser castigada si no procede con rectitud y cuya sexualidad debe ser cuidadosamente controlada. La violencia que maridos 0 parejas afectivas pueden ejercer contra las mujeres es vista en algunos países africanos, como Gambia, como un asunto privado entre el hombre y su pareja, y dicha violencia está en consonancia con la estructura familiar patriarcal de la familia y del conjunto de la sociedad, con lo que cercena las posibilidades de escape legal para las mujeres afectadas (Jabbi y otros 2020).

\subsection{Senegambia: consideración histórica y perfiles sociodemográficos generales}

Mercedes Jabardo constata la práctica inexistencia de estadísticas oficiales sobre inmigración senegalesa anterior a 1990, quedando englobada bajo el epígrafe genérico de inmigración procedente del África Subsahariana (2006: 25). Según datos del Instituto Nacional de Estadística, en 2020 había en España 5.434.153 personas de origen extranjero de las cuales el 23,2\% residían en Cataluña. La población de origen africano suponía el $22 \%$ del total estatal y el $25,7 \%$ en la comunidad catalana -que acabará convirtiéndose en un enclave de inmigración africana, especialmente senegalesa, en territorio español (Jabardo 2006: 20).

Más específicamente, estaban registradas en España 76.973 personas de origen senegalés (24.252 en Cataluña) y 21.450 de origen gambiano (15.343 en Cataluña). En los últimos años, África ha pasado a ocupar el tercer puesto en cuanto a continentes de procedencia $(20,2 \%)$, teniendo principalmente a 
Marruecos como país destacado en el origen de las personas migrantes (Consejo Económico y Social 2019: 224). En este sentido, los datos del Padrón Municipal de Habitantes de 2019 en Cataluña, muestran que la población de origen marroquí supone el 19,3\% de la población extranjera en Cataluña, seguida de Rumanía $(7,8 \%)$, China $(5,4 \%)$ e Italia $(5,3 \%)$; Senegal ocupa la decimosexta posición $(1,9 \%)$ (IDESCAT 2019). Si bien no existen datos sobre Gambia a nivel autonómico en este informe, las tablas del Padrón Continuo del INE sitúan su peso sobre el total de población extranjera en el 1,27\%. De este modo, sumando el peso relativo de ambos países, nos daría un 3,2\%, un valor muy similar al de 2011-3\% (Generalitat de Catalunya 2011; para una perspectiva evolutiva más completa de estas series migratorias, véase el Anexo I de Jabardo 2006), especialmente las págs. 157-162).

Aunque con frecuencia suele emplearse, por razones históricas, culturales, geográficas y libgüísticas, el término "senegambiano/a", Senegal y Gambia son países diferentes y con peculiaridades propias. Las fronteras políticas entre ambos países responden a tiempos coloniales, cuando Gambia y su riqueza fluvial quedó en manos inglesas y Senegal pasó a dominio francés. Aquí seguiremos el criterio de Kaplan (1998) y Goldberg (2015), quienes justifican la pertinencia del término "senegambia" para englobar conceptualmente a la población de ambos países en el terreno cultural, por cuanto las diferentes etnias que habitan el territorio "comparten orígenes históricos y culturales" (Goldberg 2015: 70), aunque en ningún caso se pretende homogeneizar culturalmente la realidad pluriétnica de dos países distintos. Además, la socióloga y experta en género senegalesa Fatou Sow (2006, cit. en Vives y Vázquez 2017) considera que en las características y estructura de los núcleos domésticos que son compartidos por diferentes grupos étnicos en la región se identifican pautas socioculturales que transcienden la diferenciación entre ambos países. En el ámbito migratorio, también es frecuente el término "senegambiano/a" para referirse a personas provenientes de estos dos países, que formaron una federación política y económica en la década de 1980 (Rodríguez-García 2006).

Demográficamente, Senegal tiene 15.85 millones de habitantes (ANSD 2014) y tiene una alta tasa de fecundidad (4.6 hijos por mujer) y de mortalidad infantil. La población es extremadamente joven (más del $55 \%$ de la población tiene menos de 20 años) y un tercio de ellos/as tiene menos de 10 años. Gambia, por su parte, tiene una población estimada de 2.2 millones de personas la tasa de fecundidad es de 5.4 nacimientos por mujer y el $42 \%$ de la población tiene entre 15 y 24 años (GBOS y ICF Internacional 2014). Aunque ambos países son formalmente repúblicas oficialmente laicas, más del $90 \%$ de la población se declara musulmana. Sin embargo, numerosas prácticas y creencias que denominan "tradicionales" no pertenecen a ninguna de estas religiones y este sincretismo atraviesa la vida cotidiana de las personas.

\subsection{Apunte sobre las mujeres senegambianas atendidas}

De las mujeres que han sido víctimas de la violencia de género en la pareja y que son atendidas en los servicios públicos, las inmigrantes son quienes se encuentran en una situación de mayor vulnerabilidad, debido a la confluencia de factores estructurales que victimizan a estas mujeres más allá de la violencia sufrida. Son especialmente relevantes en este sentido: la irregularidad administrativa, su dependencia económica, el desconocimiento del idioma autóctono de acogida y la ausencia de una red personal de apoyo en destino.

Sin embargo, según datos depurados de los expedientes del centro de acogida durante el período 2010-2020, las mujeres procedentes de África Subsahariana solo han representado el $4 \%$ del total de mujeres atendidas; aunque el $56 \%$ de ellas procedían de la zona de Senegal y Gambia y todas ellas ingresaron en el servicio con sus hijos/as (dos de ellas tenían todavía algún hijo/a en origen a cargo de las familias extensas). Las edades de los menores eran mayoritariamente de 0 a 3 años $(54,5 \%)$, seguido de 4 a $7(36,4 \%)$ y solo uno $(9,1 \%)$ tenía 11 años.

\subsection{La centralidad del matrimonio}

\subsubsection{En el contexto de origen}

Casarse es, en Senegambia, una práctica generalizada, siendo la soltería un fenómeno residual. En Senegal, la edad media de matrimonio es de 22 años para las mujeres y 29 años en los hombres (ANSD 2014), pudiendo darse edades más tempranas en áreas rurales. En Gambia, las mujeres se casan con una media de 18,6 años y los hombres lo hacen casi diez años más tarde (28). Según un informe de UNICEF de 2016 el 32\% de las mujeres contraen matrimonio antes de los 18 años y un $9 \%$ de ellas lo hace antes de los 15. La Ley de Familia fija la edad mínima para casarse en 16 años para las mujeres y 
en 18 para los hombres. La satisfacción de una compensación matrimonial a la familia de la mujer es una práctica habitual y de manera general el sistema de parentesco se basa en una ideología patrilineal y una residencia virilocal. Los matrimonios son frecuentemente organizados por las familias de ambas partes y a menudo se establecen entre primos. Sarr (cit. en Vives y Vázquez 2017) explica que son los familiares quienes deciden qué matrimonio es más apropiado y la mujer no siempre tiene poder de decisión sobre lo que eligen sus mayores. Este hecho, como corroboran varias mujeres entrevistadas en nuestra investigación, dificulta eventuales procesos de divorcio.

La poligamia es relativamente frecuente tanto en Senegal $(35,2 \%$ sobre el total, según ANSD 2013) como en Gambia (39\%, DMHS 2013). El Corán permite al hombre contraer matrimonio con hasta un máximo de 4 mujeres siempre que les pueda dar sustento, extremo que no siempre ocurre. La decisión de decantarse por un matrimonio polígamo, a menudo compartida por la pareja, responde a una estrategia de multidistribución de las tareas y cuidados en el hogar, además de aumentar la acumulación de bienes en circulación por parte de la unidad doméstica.

En línea con los resultados de Kaplan (1998) en Senegal y Gambia, nuestro trabajo confirma que estos sucesivos enlaces no se regulan de una manera estricta en el sentido de compromiso con las familias. También hemos encontrado testimonios que confirman los hallazgos de Kringelbach (2016) con relación a las experiencias personales de sufrimiento entre mujeres polígamas de Senegal y de Gambia: para muchas, formar parte de un matrimonio polígamo es una experiencia desagradable, pero a menudo responde a una estrategia de supervivencia: social y económicamente es más ventajoso ser coesposa que soltera o viuda. Así, en Dakar, las familias que pueden permitírselo distribuyen a las mujeres en diferentes casas y es el hombre quien rota, por turnos, entre ellas. Durante las entrevistas y numerosas conversaciones informales, muchas mujeres refieren que pocos matrimonios polígamos son aceptados de buena gana por ellas, y los asocian a una forma de subordinación hacia el poder masculino y familiar. De acuerdo con lo apuntado por Jabardo y Ródenas (2017, y Jabardo 2007), nuestro trabajo confirma el papel impulsor de vulnerabilidad en el contexto conyugal, al suponer un factor adicional de control masculino sobre la mujer en contextos particularmente asimétricos de poder.

\subsubsection{Consecuencias visibles en la casa de acogida}

Todas las mujeres atendidas en el servicio se habían casado por acuerdo de su familia con la familia del marido. Los relatos de las mujeres informan incluso de matrimonios concertados en los cuales el hombre, que ya ha emigrado a España, regresa para casarse, conociendo a quien será su esposa, con quien suele unirle un vínculo de parentesco, en uno de sus viajes (en un caso este arreglo ocurrió estando ya en destino: la mujer había llegado a Cataluña por reagrupación familiar de su padre y, con 16 años, fue casada con un hombre de 26 años; al cabo de un año tuvo a su primer hijo).

En este contexto institucional, la condición polígama aparece como fuente de conflictos (por ejemplo, en un caso fue motivo de discusiones entre el hombre y su primera esposa, lo que desembocó en su ingreso en el servicio por la violencia verbal, la física y las amenazas de "devolverla" a Senegal y quitarle a los/as hijos/as). De nuevo, este extremo confirma las conclusiones de Jabardo y Ródenas (2017) respecto al papel de la poligamia en las tensiones relaciones en entornos conyugales.

Por otra parte, la eventual decisión de romper con este entorno de opresión y violencia no es fácil para ellas. A las adversidades contextuales y relacionales ya consignadas, hay que añadir la condición monoparental que obligará a simultanear la crianza en solitario con el sustento material y económico del hogar. Los múltiples obstáculos burocráticos y culturales que deben enfrentar pueden ser tan formidables que algunas de ellas no ven más salida que regresar con el agresor. Quienes intentan seguir adelante son conscientes de que deberán afrontar casi en solitario todas las responsabilidades, lo que puede dar lugar a otro tipo de malentendidos culturales: unas profesionales de un servicio residencial nos comentaron cómo Isatou, una mujer senegalesa con cuatro hijos e hijas que había conseguido un empleo, se volcó completamente en su trabajo, "descuidando" [sic] así la crianza de los menores. Otra mujer nos reveló la reproducción de un modelo cultural específico: "En nuestro país nuestra costumbre es muy diferente. El papá lo que hace para los hijos es poco, muy poco, no quiero decir que no los quiera... Y aquí veo el mismo problema (...) que siempre las madres están con los niños y los padres no".

\subsection{El proceso migratorio y la reagrupación familiar}

Como señala Salazar (2010), cualquier proceso migratorio durante el periodo de crianza transforma 
profundamente las dinámicas familiares de atención y cuidado a los/as hijos/as. Además, la posible reagrupación familiar en destino está supeditada a diversos requisitos legales que condicionan su viabilidad y que pueden basarse, por defecto, en un tipo de familia nuclear relacionada con vínculos biológicos, como confirmó una entrevista con Rodrigo Aguirre de Cárcer y García del Arenal (cónsul de España en Senegal, celebrada en diciembre de 2019). Al no contemplarse la poligamia en estos procesos de reunificación, no se pueden reagrupar a diversas mujeres con toda su descendencia, lo que puede dar lugar a situaciones problemáticas en origen y en destino para las coesposas. Por ello, qué esposa acompañe al marido es una decisión familiar que sitúa a la mujer que migra en una posición delicada, recibiendo presiones de todo tipo para desenvolverse en destino y mantener simultáneamente el vínculo (y las obligaciones) con el origen. Como pudimos observar en casa de Mariama (42 años), entre los niños y niñas que allí moraban, estaba una de las hijas de un matrimonio reagrupado que vivía en Italia. En palabras de Mariama, tener a esa niña (sobrina suya), es una garantía de que su hermana "no se olvide" de su familia senegalesa (incluyendo el envío de remesas económicas).

Por lo que a la casa de acogida se refiere, a excepción de una joven (16 años) reagrupada por su padre, todas las mujeres llegaron por reagrupación familiar del marido. En los casos analizados, esta reagrupación ha tardado más de dos años en formalizarse y cuando la mujer emigra normalmente lo hace ya con un hijo o hija, engendrado durante alguno de los retornos del esposo. Las mujeres reagrupadas dependen totalmente de sus maridos para regularizar su situación administrativa, lo que estos usan como mecanismo de control sobre ellas (por ejemplo, decidiendo si les tramitan o no el NIE). Además, si la denuncia por violencia no es aceptada a trámite o no obtienen una sentencia favorable, no podrán regularizar su situación, quedándose legalmente aún más desprotegidas.

\subsection{Violencia de género}

\subsubsection{En el contexto de origen}

Pese al escaso volumen de denuncias presentadas (Leye 2017), la violencia de género en Senegal es una práctica habitual anclada culturalmente en un régimen patriarcal (situación que Jabbi y otros 2020 también constatan en Gambia). Según un estudio llevado a cabo entre la Agencia Nacional de la Estadística y de la Demografía (ANSD 2014) y ONU FEMMES (Houinato 2017), un 24\% de mujeres en pareja o separadas reconocen haber sufrido violencia emocional, física o sexual por parte de sus parejas o exparejas. En el ejercicio de estas formas de violencia, algunas situaciones que, en origen, se consideran culturalmente aceptables comprenden ser considerada una cuidadora negligente de sus hijos/as, rechazar tener relaciones sexuales con su pareja, salir de casa sin consentimiento o quemar la comida que está preparando (observación congruente con los hallazgos referidos por Bop 2010 en Senegal bajo estos mismos contextos de dominación conyugal).

Según Leye (2017), en conjunto, el $57 \%$ de las mujeres justifica la violencia en alguna de las situaciones propuestas, principalmente quienes trabajan y no reciben retribución económica en dinero $(68 \%)$ y quienes tienen más hijos (65\% de mujeres con 5 hijos). Además, influye el estado civil: las mujeres en pareja o casadas justifican más la violencia (61\%) que las separadas, divorciadas o viudas (51\%) y menos las que permanecían solteras $(48 \%)$. En contexto urbano se justifica menos (43\%) la violencia que en rural $(69 \%)$ e igual ocurre entre las mujeres con un grado de formación media o superior $(40 \%)$ respecto a las de estudios primarios o sin instrucción (68\%), porcentaje que en otros estudios asciende al $82,4 \%$. El grado de aceptación de este tipo de violencia también disminuye con la mejora en el nivel de bienestar del hogar en el que vive la mujer. La justificación de la violencia por parte de la pareja afecta al $81 \%$ de los hogares del quintil de ingresos más bajo y al $36 \%$ de los más altos.

Sengún el Demographic and Health Survey de Gambia (DMHS), en este país el $26 \%$ de las mujeres casadas reconoce haber sufrido violencia física emocional o sexual por parte de su esposo o pareja y $41 \%$ de las mujeres de 15 a 49 años dicen haber sufrido "violencia doméstica" de tipo físico al menos una vez en su vida (GBOS y ICF Internacional 2014). Además, el $5 \%$ reconoce haber sufrido violencia sexual en algún momento de su vida. Las mujeres que justifican esta violencia suelen trabajar sin contraprestación dineraria $(67 \%)$, están casadas $(63 \%)$ y viviendo en zonas rurales $(73 \%)$. Esta complacencia tiende a decrecer en mujeres con mayores ingresos económicos.

Un estudio sobre la Violencia de Género llevado a cabo por la Universidad de Gaston Berger de Saint Louis explica cómo el $20 \%$ de las mujeres que sufre violencia de género en el ámbito doméstico en Senegal lo hace en silencio y resignación, debido a la estigmatización social que pueden sufrir ellas y sus familias (Diop 2015). Además, la consideración del padre como cabeza de familia hace que, en algunos 
casos, los/las niños/as sean separados de las madres cuando estas no pueden acreditar solvencia financiera. Este es el caso de Bintou (29 años), una mujer senegalesa, empleada doméstica y divorciada quien, tras no poder acreditar una buena situación económica post-divorcio, vio como su hijo fue a vivir a la casa de su abuela paterna, en otra ciudad, donde permanecería hasta que ella pudiese acreditar mantenerle. Los familiares de Aida (32 años), profesora de escuela pública en Senegal, trataron de disuadirla de su intención de divorciarse y le explicaron que romper con su marido le obligaría a enfrentarse a su familia "política", que no deja de ser una parte de la familia extensa. Aida siguió adelante y posteriormente nos comunicó que dar esas explicaciones a la familia fue la fase más difícil de su divorcio; mucho más que perder todos los muebles o tener que acreditar bienes suficientes para poder mantener la custodia de sus hijos (véase un estudio etnográfico detallado de los procesos de demanda y de resolución en casos de violencia de género en Senegal en London 1999).

\subsubsection{Tras ingresar en la casa de acogida}

Aminata, una joven en Cataluña, de padre y madre senegaleses, explicaba que, en origen, se minimiza el impacto de la violencia que ejerce el hombre contra su esposa y si decide abandonar o denunciar a su marido, se ejerce sobre ella una presión que va más allá del ámbito familiar: "El hombre le dice a sus amigos que la mujer le quiere dejar, ellos van a hablar con la mujer". En el servicio hemos podido observar la influencia que tiene sobre la mujer la familia extensa y la comunidad, incluso desde la distancia, a través de constantes llamadas telefónicas animándola a regresar con el marido y amenazándolas y calificándolas de "malas madres" por impedir que los hijos puedan estar con su padre.

Entre las mujeres atendidas encontramos, en línea con estudios anteriores (Sorribas y Gracia 2004, Moriana 2018), que estas mujeres muestran un elevado nivel de tolerancia a la violencia (sea esta psicológica, física o sexual). La presión económica se convierte en un detonante para denunciar la situación cuando se estima que no pueden garantizar el bienestar de los hijos e hijas, así como la discrepancia con las decisiones del marido, por ejemplo, ante la inminencia de un segundo matrimonio.

En estas situaciones, además, debe prevenirse el posible sesgo etnocéntrico de quienes intervienen profesionalmente en el proceso de acogida. Por ejemplo, Menjivar (2002) expone cómo pertenecer a un grupo étnico u a otro puede condicionar las intervenciones que se realicen por parte de los agentes que intervengan, asumiendo que se trata de una práctica culturalmente aceptada y, por ello, menos problemática.

\subsection{Organización familiar y vida cotidiana}

\subsubsection{En el contexto de origen}

Vives y Vázquez (2017) explican que la precocidad de los matrimonios, el modelo de familia basado en la convivencia de diferentes generaciones bajo el mismo techo, y la práctica del matrimonio polígamo, son factores que explican el gran tamaño de la familia senegalesa, que puede llegar a ser de hasta ocho miembros (ANSD 2014). El poder reside en el "cabeza de familia" (como consta en el código de familia senegalés) y son las mujeres quienes asumen íntegramente el cuidado y el mantenimiento de la casa. Este hombre es el principal proveedor económico, lo que adquiere gran relevancia en un contexto donde recibir dinero no es habitual y muchos sueldos son retribuidos en especie.

En los hogares polígamos, la distribución monetaria de este sustentador principal se realiza durante los turnos de pernoctación con sus sucesivas esposas. Sin embargo, si el dinero aportado por este hombre es insuficiente, las mujeres pueden trabajar fuera de casa. Pese a que en entornos urbanos esta situación es cada vez más frecuente, sigue asumiéndose que la mujer debe encargarse prioritariamente del ámbito doméstico.

Los varones ancianos asumen el poder simbólico dentro del núcleo familiar, aunque las mujeres de cierta edad también tienen un considerable peso específico. Tanto es así que, en hogares donde algún hijo ha emigrado, es generalmente su madre quien recibe y distribuye las remesas. Aunque durante el trabajo de campo diversas informantes insistieron en que este es un rasgo propio de la etnia wolof, dicha forma de distribución se ha observado también en otros grupos étnicos de la zona. Así, el hombre migrante confía la remesa económica a su madre y no a su esposa, y es el criterio de la primera el que prevalece en su reparto. A la esposa suele quedarle una pequeña parte, tanto si está en origen como si está en destino. Las demás mujeres convivientes se hacen cargo del cuidado de la casa, así como de sus ocupantes mayores y pequeños, independientemente del vínculo biológico que les una. La intensidad de la 
dedicación tiene que ver con criterios de edad y posición en el grupo (primera esposa, segunda o sucesivas, si se es hija o sobrina, etc.) siendo las mujeres jóvenes sin hijos quienes más trabajan.

Junto con las relaciones de solidaridad que se establecen entre mujeres en el interior de los núcleos domésticos (Jabardo y Ródenas 2017), las relaciones entre ellas no son siempre fluidas: las responsabilidades son muchas, el trabajo es arduo y pesado y los recursos, generalmente escasos, se distribuyen asimétricamente, teniendo preferencia los miembros varones de la familia. En sintonía con lo consignado por Kaplan (1989), la crianza en casa se asume como una responsabilidad femenina, dándose con frecuencia lo que Vives y Vázquez (2017) denominan maternidad colectiva: tanto mujeres adultas como menores cuidan conjuntamente a todos los/las niños/as que en ella habitan. De hecho, durante el trabajo de campo no es sencillo identificar lazos maternofiliales específicos, por cuanto las mujeres dedican atenciones equivalentes a todos los niños y niñas que rondan, excepto cuando son bebés muy pequeños. Las mujeres entrevistadas explicaban que tratar mejor al hijo no biológico que al tuyo se considera un deber social puesto que, como nos decía Anouk (32 años), cuando crecen "se acuerdan de quienes les cuidaron".

\subsubsection{Experiencia en la casa de acogida}

Las mujeres que han sido atendidas en la casa procedían básicamente de zonas rurales. Cuando llegan al servicio con sus hijas e hijos se les facilita ropa de cama y de baño para todos los miembros del núcleo familiar. Cuando ingresa un bebé se proporciona a la madre una cuna, aunque suele acabar convirtiéndose en un recipiente para guardar juguetes o ropa; la razón es simple: en origen los bebés duermen con su madre en la misma cama, para que puedan ser amamantados a lo largo de la noche.

Durante su estancia en el centro, las mujeres explicaban que el vínculo de parentesco que les une a sus maridos añade presión a las mujeres: son primos o familiares lejanos, e incluso en un caso el padre de la mujer se casó con una segunda esposa, que, a su vez, concertó el matrimonio de su hermano con la hija del esposo. El peso e influencia de la familia es tan importante que, incluso en la distancia, la toma de decisiones sigue atendiendo al criterio de los miembros relevantes de la misma. Así, las mujeres se encuentran a menudo ante una doble presión. Por un lado, la de algunos equipos profesionales, externos al circuito de recursos especializados en violencia de género, que insisten en que se denuncie al agresor o abandone el domicilio; las profesionales expertas en violencia machista tienen muy claro que no puede obligarse a una mujer a denunciar, sin embargo, esa presión suele darse en otros contextos profesionales y en especial cuando se detectan los riesgos. Y, por otro lado, la de sus familiares, que quieren que retiren la demanda y regresen con sus maridos, so pena de perder a los niños.

La precariedad económica de la mujer juega también un rol fundamental cuando están en destino, tanto a nivel material como simbólico. Una mujer que llegó a España por reagrupación familiar con un primer hijo nacido en Senegal (y que tuvo el segundo hijo ya en Cataluña) nos decía lo siguiente:

"cuando nació mi hijo grande, mi marido envió mucho dinero para comprar lo que se necesitara, pero cuando ha nacido el pequeño le digo 'esta vez no me has dado nada de dinero' y dice, 'claro ya te lo he dado porque me lo he gastado aquí, he comprado carro, cuna', lo que sea, para el mayor no necesitábamos todo esto alli".

La solidaridad entre mujeres se aprecia en espacios de crianza, como el ejercicio de maternidad colectiva a que se refieren Vives y Vázquez (2017), aunque es una práctica difícil de llevar a cabo en el servicio, por dos grandes razones. En primer lugar, porque algunas tareas que suelen recaer en hermanos/as mayores (preparar desayunos, vigilar el comportamiento de los pequeños, etc.) chocan con normas que estipulan que, por razones de seguridad, los menores no pueden trastear en la cocina. Y, en segundo lugar, porque cuando un/a hijo/a asume funciones de cuidado, las profesionales del servicio se apresuran a desadultizar a esa niña o niño, transmitiéndole a la madre que esas responsabilidades no corresponden a un/a menor de su edad (pretenden, así, reparar algunas consecuencias de la violencia machista en la pareja, como que algunas niñas y niños deban asumir responsabilidades que, como los cuidados y la protección, por edad no les corresponden). Por tanto, una inadecuada contextualización de esta práctica puede revertir, en algunos contextos profesionales, en una valoración negativa de la conducta materna.

Por otra parte, en la casa se fomenta que cada mujer esté pendiente de sus propios hijas e hijos, para evitar conflictos entre las madres debido, por ejemplo, a discusiones o peleas entre ellos/as. De nuevo, esta disposición colisiona con prácticas tradicionales de maternidad colectiva. 
A este respecto, durante el trabajo de campo hemos observado que se establecen relaciones de mayor confianza entre mujeres que tienen un origen próximo. Sin embargo, una mirada estrictamente técnica (no exenta de cierto etnocentrismo), no suele conceder importancia a esta variable: los datos proporcionados por los servicios que derivan no recogían a menudo el origen étnico ni la lengua materna de la mujer, solo su nacionalidad, cuando son factores muy valorados por las propias mujeres en su dinámica cotidiana. En uno de los casos se solicitaron los servicios de una traductora para comunicarnos con la mujer (solo hablaba wolof). La entrevista transcurrió con evidente incomodidad por su parte, que el equipo interpretó como inherente a las dificultades que muchas mujeres víctimas de violencia experimentan al relatar sus vivencias. Sin embargo, cuando la traductora se fue, la mujer logró explicar que no le gustó porque era de etnia fula (aunque hablaba correctamente wolof).

Del mismo modo, más allá del colectivo gambiano y senegalés, las diferencias étnicas pueden tener más peso que la solidaridad o la sororidad entre las mujeres, dificultando la empatía aun hallándose en circunstancias parecidas. Las relaciones entre ellas se sustentan en sus respectivos orígenes étnicos, produciéndose una "jerarquización informal" en la que las mujeres procedentes de la llamada África subsahariana suelen ser las menos aceptadas por el resto (i.e. europeas, latinoamericanas 0 marroquíes). Por consiguiente, la convivencia obligada con personas de otros orígenes étnicos puede constituir un factor estresante adicional.

Por otra parte, ninguna de las circunstancias en que se encuentran las mujeres que sufren maltrato puede aislarse de la consideración social que reciben en tanto que migrantes de países pobres, ni de la evidente carga etnocéntrica de algunas consideraciones acerca de su forma de criar o de relacionarse entre ellas. Un etnocentrismo, por cierto, del que tampoco escapan las propias mujeres del área senegambiana a la hora de evaluar las conductas de residentes de otras regiones del planeta. No obstante, las consecuencias de uno y otro proceder son, a efectos prácticos, considerablemente distintas.

Sea como fuere, su institucionalización implica la convivencia en una casa de acogida, donde comparten espacios con otras personas (también dañadas, pero de contextos culturales muy distintos) y en la que se replican prácticas desconocidas para estas mujeres que deben incorporar a toda prisa. Además, la paliación de su vulnerabilidad psicológica, social y familiar recae sobre un conjunto de profesionales que intervienen en el marco de un programa de acompañamiento, aportando una buena dosis de saber experto, pero sin disponer a veces de las herramientas adecuadas para gestionar la diversidad étnica y cultural con que se encuentran. En este sentido, en las instituciones de atención esta carencia puede condicionar la mirada experta sobre las distintas formas de pensar, sentir y actuar y puede comportar una (indeseada) vulnerabilidad adicional.

En este contexto es especialmente importante establecer una relación de confianza entre la mujer y el equipo de intervención. La joven hija de una pareja senegalesa nos comentaba que la desconfianza está muy presente en las relaciones interpersonales, incluso entre las mismas mujeres migradas y de zonas geográficas cercanas: "cuando alguien les ofrece ayuda o cuando alguien quiere quedar con ellas, '¿qué me pedirá?'”. Para la cimentación de esta confianza es imprescindible conocer y entender los referentes culturales que contextualicen y expliquen sus necesidades, revelen los problemas a los que deberá enfrentarse (en destino y en origen) y ayuden a diseñar propuestas concretas y adecuadamente orientadas de intervención. $Y$ a menudo esta comprensión no refiere a grandes referentes culturales (preceptos religiosos, por ejemplo), sino que se demuestra en (aparentemente) pequeños detalles como el uso de las mantas en la cama o juzgar sus hábitos higiénicos o de organización sin tomar en cuenta que esa es precisamente la forma adecuada de hacerlo en origen.

\subsection{Tener (y criar) hijos/as}

\subsubsection{En el contexto de origen}

Tras el matrimonio, la familia y el grupo social más próximo alientan la pronta llegada de hijos. Para una mujer, no quedarse embarazada pocos meses después de casarse atrae más presión sobre ella, ante la sospecha de infertilidad (generalmente considerada una causa femenina). Sin embargo, tener hijos no comporta una disrupción completa con la vida anterior ya que cuando una mujer da a luz suele haber cuidado, dormido, acunado e interaccionado ya con muchos otros niños/as. Como hemos visto, esta exigencia de cuidado se extiende incluso en casos de separación familiar temporal por migración, una situación frecuente al tener prácticamente todas las familias algún pariente que ha viajado y retornado periódicamente al hogar desde diferentes países (González-Ferrera y otros 2012). 
A lo largo del trabajo de campo se aprecia que el supuesto ideológico occidental de maternidad exclusiva "construido en torno a la experiencia de la maternidad biológica basada en tres principios: 'que todas las mujeres deben ser madres, que todas las madres necesitan a sus hijos y que todos los niños necesitan madres"' (Oakley 1974, 186 en Vives y Vázquez 2017; énfasis añadido) dista de ser compartido por las mujeres en sus países de origen, quienes suelen apoyarse en un principio más colectivo de crianza, como hemos visto. Con esto no queremos decir que no exista un vínculo especial entre una madre y su progenie biológica, sino que la responsabilidad del cuidado y la educación de los niños adquiere una dimensión social más amplia, que va modulándose en función de la edad del/la menor.

Así, siguiendo a Kaplan (1998), podemos constatar que la relación de las madres con sus hijos e hijas recién nacidos es muy intensa, pasando la mujer prácticamente todo su tiempo con el bebé, porteándole en sus actividades domésticas; si necesita dejarlo con alguien, lo hará con personas de su entorno, en brazos de quien esté más cerca para que juegue con él, lo acune, o lo lave, independientemente de la edad que tenga este cuidador (puede ser un/a niño/a relativamente joven). En estos primeros meses, los menores siempre están acompañados y duermen con su madre en colchones, a veces cubiertos por una gruesa manta. Cuando el menor comienza a caminar, pasa más tiempo en pequeños grupos de niños/as de su edad y la atención de la madre se dispersa, pudiendo ser atendidos por otros niños/as mayores a cargo de su seguimiento.

En cuanto los/as niñas pueden andar, comienzan a circular por la casa y sus alrededores, en compañía de otros menores de edad similar. Además de jugar, puede encomendárseles tareas sencillas como, por ejemplo, llevar comida de una casa a otra en bandejas que cargan sobre sus cabezas. Cuando se enzarzan en peleas o molestan a los mayores, puede recurrirse al castigo físico. En las casas no hay "juguetes", entendidos como artefactos construidos con la finalidad de que los niños jueguen, sino que se les permite tocar y examinar casi cuanto tienen a su alcance, en una suerte de inmersión en el mundo adulto. Una mujer explicaba cómo antes había menos accidentes domésticos y era más fácil habilitar espacios donde, por ejemplo, se cocinaba con fuego: sacaban los enseres y había una persona constantemente vigilando que ningún pequeño se quemase con la lumbre o se cortase con un cuchillo. Al acabar, apagaban el fuego y los utensilios volvían a guardarse. Pero ahora, decía, las cocinas actuales son más estáticas y tienen multitud de elementos que permiten a los niños explorar en ausencia de personas vigilantes, lo que les expone a sufrir más accidentes. De hecho, la distribución de espacios y la regulación de su uso son, en una casa de acogida, muy distintas a las que pueden apreciarse en un hogar de Senegal o de Gambia, donde la funcionalidad sigue un criterio mucho más flexible.

Al igual que cuando son bebés, en estas edades no hay una intencionalidad educativa verbalizada, sino que este participa en el mundo adulto, en sus conversaciones, escuchando sus actividades. En diferentes entrevistas se pudo observar cómo los pequeños circulan con libertad por la casa y la interacción con los adultos consiste básicamente en que estos les sorteen en sus paseos, les consuelen de manera puntual si se quejan, cambiándoles de lugar, o cogiéndoles en brazos. Además, la crianza compartida genera situaciones en que hay una previsión de otras personas atendiendo a un niño/as que deambula por una casa. Esta ampliación de las responsabilidades de crianza más allá de la figura materna ejemplifica las lógicas de ayuda mutua y de solidaridad entre mujeres que han apuntado anteriormente autoras como Sandu (2013) o Jabardo y Ródenas (2017).

A partir de los 5 o 6 años comienzan a asumir responsabilidades diferenciales en el hogar y con 10 años una niña ya puede llevar una casa, momento en que desaparece gradualmente del espacio público y comienza a asumir tareas domésticas asociadas a las mujeres. Los niños de la misma edad, por contra, extienden su etapa de exploración e interacción en el exterior de la casa. En este periodo, la influencia de la madre pierde peso y el padre asume mayormente su formación, aunque por las noches siguen durmiendo con ella.

A partir de los 9 o 10 años se intensifica el control familiar sobre las niñas. A esta edad la percepción es que los jóvenes ya son maduros y nadie suele intervenir sobre sus conflictos o riñas. Ambos géneros segregan aun más sus tareas: las niñas cocinan y realizan todo tipo de tareas domésticas y los niños comienzan a ayudar en casa y deben dar muestras de un comportamiento apropiado (aunque disfrutan de más libertad que sus hermanas). Durante este periodo, los niños acuden a las escuelas públicas o a los centros coránicos donde inician su educación religiosa. Las madres, frecuentemente, imponen una estrategia de distancia física y emocional relacionada con la idea de formar a un adulto capaz de regular su propio comportamiento.

Así, siguiendo a Spindler (1993), las madres educan a sus hijos e hijas para que aprendan a pensar, a 
sentir y a actuar de un modo adecuado al sistema cultural en el que viven. Por ello, tanto en Gambia como en Senegal, inciden especialmente en determinados valores: la sumisión a los adultos (sobre todo a los padres), el autocontrol, el autodominio de las pasiones, la aceptación de lo que llega, el no mostrar miedo, saber redistribuir, respetar a la familia, tener paciencia y, especialmente, tener un buen dominio de sí mismo y ofrecer siempre la mejor cara. Para alcanzar satisfactoriamente estas metas pueden recurrir a la distancia emocional, lo que en ocasiones es (mal)interpretado desde otros parámetros culturales como muestra de desinterés o incluso negligencia en el cuidado. Por ejemplo, durante una visita a casa de Awa (28 años) una niña de unos dos años salió de una habitación con un zapato de adulto en la boca. La madre no estableció contacto visual con ella en ningún momento y la pequeña se dio la vuelta; en aquel momento, una prima mayor, sin mostrar preocupación aparente, le quitó el zapato con un gesto rápido. Tras esto, la niña volvió a entrar sola al cuarto, quedando de nuevo fuera del campo de visión de la madre.

Escenas como esta son habituales en los hogares de origen y si estas conductas se reproducen en destino, pueden dar lugar a lecturas erróneas respecto a las habilidades parentales de las madres. Para ellas es importante que sus hijos e hijas adquieran autonomía y se preparen para una vida adulta que requerirá de toda su fortaleza. Actuar de otro modo, aseguraban, les convertiría en niños "mimados" o "enmadrados". Según contaban algunas madres, enfrentarse desde una edad temprana a situaciones duras, a soportar decisiones familiares no siempre deseables y a la asunción de responsabilidades familiares, les ayudará también a emprender, sin amilanarse, procesos migratorios que entrañan no pocos riesgos. Paralelamente, la vivencia en colectividad y la exigencia de la solidaridad y de compartir, en lugar de acumular para sí, los prepara también para la obligación de apoyar a quien deben hacerlo (así como de reclamar el derecho a ser apoyados cuando proceda).

Si estos valores no se mantienen en el lugar de destino, el propósito se malogra. Por ejemplo, Haja (42 años) tiene una hermana que emigró a Italia y nos relataba que cuando esta vuelve con su hija de 8 años parece otra niña: "no quiere comer de nuestras tazas y platos, todo le da asco". Asegura que esta forma de educarles les convierte en niños "mimados" y que así no se les prepara como "seres humanos".

\subsubsection{Experiencia en la casa de acogida}

Un aspecto en el que hacen hincapié las mujeres atendidas es la importancia de la compensación matrimonial que reciben sus progenitores, ya que supone la garantía de la familia del novio sobre los derechos de reproducción; esto es: sobre los hijos e hijas que se integrarán en el patrilinaje del padre. Las mujeres aducen que esta práctica, recogida en el código de familia senegalés, confiere a la familia del marido la potestad de quedarse con sus hijos e hijas, frecuentemente tras una presión intensa y sostenida por parte de su familia extensa en origen y que se proyecta incluso sobre el entorno más cercano de la mujer en destino.

Otro factor que subrayan son las múltiples diferencias en la crianza después del parto. Por ejemplo, Mariama, que había tenido su primer hijo en Senegal y el segundo en Cataluña, comentaba que:

"Aquí hay más comodidad que allá, el tema del pañal, el tema de la comida, el tema de las revisiones del médico (...) llevo aquí diez años y allá poco a poco están mejorando muchas cosas. Por ejemplo, allí cuando tuve a mi hijo lo tuve en casa y aquí en un hospital, son dos cosas súper-diferentes (...) cuando ha nacido mi hijo pequeño aquí me he cansado mucho, porque cuando nació el grande allí, entre mis hermanas, la madre de mi marido y mi madre, en realidad solo hacia que darle el pecho, que si lo tenía mi madre, la madre de mi marido o mis hermanas yo no hacía nada. Y aquí cuando ha nacido el pequeño, claro, cuando empezaba a llorar llamaba a la mi madre y le decía 'El niño está llorando, ¿qué hago?', y yo también me ponía a llorar, en aquel momento te sientes sola...”.

Otra mujer relataba el sufrimiento que supuso para ella dar a luz a su hijo sola, en un hospital, cuando en Gambia todas las mujeres de la familia acompañan en el parto.

Ante esta ausencia de apoyo familiar durante el primer año, las mujeres esperan de sus hijos e hijas más mayores un funcionamiento más autónomo.

En la casa de acogida se observan también este tipo de comportamientos. Pese a que hay mujeres que se muestran muy rígidas en las normas durante las comidas (no hay que levantarse de la mesa mientras se come, deben utilizarse correctamente los cubiertos, etc.), en general se observa un nivel muy elevado de autonomía de los niños y niñas en cuento a la preparación del plato y la madre puede estar 
prácticamente ausente en esos momentos. A partir de los 5 o 6 años, son los propios menores quienes preparan su plato o se hacen el desayuno, generalmente bajo la supervisión de un hermano o hermana mayor que asume muchos aspectos de la crianza.

En el servicio de acogida, las mujeres senegalesas y gambianas son muy críticas cuando los hijos de otras mujeres se muestran desobedientes y les reprochan no saber inculcar el debido respeto hacia una figura adulta. Cuando el hijo o la hija de una madre senegambiana actúa de un modo irrespetuoso (lo cual hemos observado pocas veces), les impone un castigo que considera ejemplar. Durante las conversaciones con ellas insistían en que quieren "lo mejor" para sus hijos y eso incluye poder escolarizarlos en destino y que sigan sus estudios con aprovechamiento. Es en este contexto institucional donde se visibiliza con claridad la importancia que adquiere la diversidad cultural en las relaciones entre personas que están atravesando una situación parecida.

Dos aspectos dificultan que en ocasiones se establezcan relaciones basadas en el apoyo mutuo y la sororidad. La primera está relacionada con los efectos de las violencias vividas (desconfianza hacia otras personas, dificultad para establecer relaciones interpersonales, etc.), y la segunda apunta a las diferencias étnicas y fenotípicas de las mujeres.

\section{Conclusiones y orientaciones para la intervención}

\subsection{Conclusiones}

El ingreso de mujeres de Gambia o Senegal en casas de acogida pone de relieve la presión social que experimentan muchas de ellas, tanto por parte de sus entornos relacionales más próximos en origen como en destino. En este sentido, nuestras observaciones coinciden con los estudios previos de Bop (2010) y Plaza Aleu (2012) en lo relativo al ejercicio de la violencia sobre las mujeres como una consecuencia directa de la desigualdad de género, tanto en origen como en destino, y a la condición subordinada de la mujer en los espacios domésticos y familiares. La decisión de migrar por reagrupamiento familiar incrementa su vulnerabilidad, por cuanto fragmenta el núcleo familiar, pierden apoyos en origen y se altera radicalmente la posición particular que pasan a tener dentro de la familia una vez llegan a España. Además, su capacidad de subsistencia se resiente, ya que las remesas económicas se envían a las casas de sus maridos (en origen), mientras ellas disponen de recursos muy limitados en destino. Este hecho, como Jabbi y otros (2020) han puesto de relieve, refuerza la capacidad de control del marido sobre la mujer, pudiendo usar la denegación de ayuda para regularizar la situación de la esposa como un mecanismo inhibidor de la conducta que puede obligarlas a permanecer en casa cuando él decida y restringir considerablemente su capacidad de movimiento. Como refieren algunas mujeres atendidas, este aislamiento social empeora notablemente las consecuencias del maltrato.

Además, la comparación de prácticas culturales en origen y en la casa de acogida, permite confirmar los resultados de estudios precedentes (Kaplan 1998, Sorribas y Gracia 2004, Kringelbach 2016, Moriana 2018) al identificar diversos factores que, concatenadamente, inciden en la vulnerabilidad de estas mujeres, así como de sus hijas e hijos, en el marco de la violencia de género: a) aislamiento social ejercido por el agresor como forma de control, b) dificultad resultante para el aprendizaje de idiomas autóctonos en destino, c) dificultad para familiarizarse con las normas sociales de su nuevo entorno social, d) limitaciones para incorporarse al mercado laboral, incluso en sectores de economía sumergida, y e) precariedad económica. Además, su situación de irregularidad administrativa y la dependencia económica de su marido influyen decisivamente en la posibilidad del acceso a una vivienda propia.

Este cúmulo de circunstancias explica que una gran mayoría de estas mujeres no hayan trabajado fuera del ámbito doméstico y, cuando se han visto obligadas a hacerlo, se han encontrado con una sucesión de murallas legales y culturales que desactiva prácticamente cualquier opción de independencia, como han señalado Jabbi y otros (2020), situación que se agrava con el padecimiento de amenazas y malos tratos. Además, como ya constataron Arnoso y otros (2012), el advenimiento de crisis económicas como la desatada en 2008 puede comportar la pérdida del empleo por parte de sus maridos y agravar en muchos casos las situaciones de violencia doméstica cuando estos no sobrellevan bien perder (o no poder ejercer) la condición de sustentadores principales.

En nuestro trabajo, hemos visto cómo el saber experto carece en ocasiones de instrumentos adecuados para gestionar la diversidad cultural y esto puede inducir una vulnerabilidad adicional sobre las mujeres al 
sesgar ideológicamente su intervención. Para prevenirla, conviene tener en cuenta la situación global de cada mujer, desde una mirada que permita comprender sus prioridades culturales y las consecuencias que su situación y sus decisiones le acarrean también en origen. La gravedad de las mismas se evidencia cuando algunas mujeres que ingresan en el servicio debido la violencia de género en la pareja, comentan que para ellas es un problema menor: su principal preocupación es poder atender y mantener adecuadamente a sus hijos e hijas y hacerlo desde sus propios códigos y prioridades culturales.

No debe olvidarse, además, que las mujeres que ingresan en estos centros de protección están en una situación de vulnerabilidad múltiple y enfrentarse a un cuestionamiento adicional de sus prácticas y costumbres habituales no contribuye a su comodidad ni fortalece sus recursos de afrontamiento. Es fundamental establecer una relación de confianza mutua que exige, entre otras cosas, deponer los estereotipos étnicos y los imaginarios culturales que, como ha explicado bien Aixelà (2006 y 2013) pueden dificultar la integración social de estas mujeres, especialmente en entornos tan sensibles como el de la violencia por parte de sus parejas.

Por otro lado, hemos visto cómo la importancia que el entorno familiar tiene para una mujer durante el periodo de crianza en el país de origen debería ser tenido muy en cuenta a la hora de encarar las actuaciones pertinentes de intervención. Para muchas mujeres sería inviable renunciar a sus relaciones familiares (téngase en cuenta que las familias presentan conformaciones extensas que se ramifican en otras conexiones sociales con entornos relacionales próximos) y difícilmente podrán aplicarse estrategias de intervención que supongan una extracción completa de la mujer de ese entorno.

Por último, nuestro trabajo revela también la importancia que adquiere el apoyo mutuo entre mujeres, especialmente en entornos de crianza, sobre todo en origen. Esta ayuda compartida puede considerarse un exponente de lo que Sandu (2013) ha denominado sisterhood solidarity y cuyas lógicas de intervención no pueden dejarse de lado a la hora de comprender las estrategias de crianza y de organización de la vida cotidiana entre mujeres que, en destino, se encuentran atrapadas en una espiral de desigualdades de género, étnicas y económicas (además de los estereotipos patriarcales) que las mujeres migrantes deben afrontar.

\subsection{Orientaciones para la intervención}

Nuestra investigación puede ser de utilidad tanto para las administraciones que diseñan los mecanismos de protección como para los/as profesionales que gestionan la vida diaria en los centros de acogida. Algunas orientaciones útiles que podemos aportar en este sentido, y que convendrá profundizar en futuros estudios, son las siguientes:

-No puede entenderse la realidad de las madres senegalesas y gambianas en los entornos de institucionalización sin un conocimiento más amplio de los referentes culturales que regulan en origen la crianza de sus hijos (y que frecuentemente implica un cuidado colectivo que trasciende incluso la propia unidad familiar de origen).

-El relato de estas mujeres es muy importante para encajar sus trayectorias personales en el seno de tradiciones culturales más amplias. En este sentido, la crianza no responde a unos parámetros culturales idénticos a los que conforman el imaginario del cuidado en nuestro entorno social, sino que resultan de integrar distintos referentes respecto al género, el matrimonio, el divorcio, la espiritualidad, las relaciones con los otros, etc.

-En consecuencia, debemos entender la institución de acogida como culturalmente orientada, desentrañar los supuestos propios que la estructuran y permitir la entrada de otros distintos para poder hacer de ella un entorno culturalmente sensible.

-Al acompañar a estas mujeres debemos negociar culturalmente, como refería San Román (1996), lo que implica ser capaces de renunciar al poder que nos proporciona ser trabajadores/as blancos/as en instituciones sociales nativas. Esto supone estar dispuestos/as a redimensionar ciertos valores e ideas que desde nuestras coordenadas culturales pueden ser tan importantes como "el orden", lo "verdaderamente nutritivo", o la "limpieza" para incorporar valores y referentes que formen parte de los universos simbólicos de las personas para quienes trabajamos.

-Debemos también reconocer que las elecciones de las mujeres están relacionadas con la situación de vulnerabilidad que padecen y algunas decisiones que tienen que ver con su cuerpo y con sus vidas 
responden más a este daño que a cuestiones culturales. Así, debemos ser conscientes de que trabajamos con personas vulneradas y dañadas, que pueden haber sufrido múltiples experiencias de alterofobia y para quienes el entorno en el que se desenvuelve puede resultar considerablemente hostil.

-En este sentido, debe trabajarse desde un enfoque terapéutico y crítico, consciente de la diversidad cultural y de la condición vulnerable de las personas atendidas, donde la intervención se encamine a convertir la institución en algo vivible y amable para las mujeres que la frecuentan. No debe perderse de vista que son mujeres que han demostrado una gran resiliencia a múltiples formas de violencia, que han tomado una decisión con un alto coste (emocional y material) para ellas y que atesoran numerosas habilidades y capacidades que no conviene desestimar. Las intervenciones no deben, por tanto, acometerse desde una mirada asistencialista o paternalista.

En consecuencia, para evitar que el trabajo de atención e intervención que se da en los recursos residenciales orientados a la protección de mujeres con hijos e hijas menores de edad pueda constituir, involuntariamente, un factor adicional de vulnerabilidad, conviene atender a tres factores principales:

1) La situación de origen de las mujeres atendidas en el servicio, su propia vivencia y concepción de la violencia machista, y la forma en que se considera culturalmente adecuado criar a un/a hijo/a.

2) La diversidad de referentes étnicos entre las mujeres acogidas, que puede comportar que ni la regulación normativa de la convivencia cotidiana en el centro, ni las formas culturalmente distintas de vivir y criar sean compartidas o fácilmente aceptadas por todas las convivientes.

3) Las consideraciones de los equipos psicosociales de intervención sobre las pautas y prácticas de crianza más adecuadas para el óptimo crecimiento y desarrollo de un niño, niña o adolescente deben tener en cuenta en cada caso el contexto étnico de referencia, para no generar orientaciones disruptivas en contextos psicológica y emocionalmente muy sensibles.

Nuestro trabajo también presenta dos limitaciones principales. En primer lugar, la imprescindible garantía de confidencialidad que envuelve a cada caso impide proporcionar más información relativa al centro, los perfiles de las mujeres o algunos detalles contextuales que pudieran ser reveladores. Por esta razón, en este artículo hemos optado solo por incluir pseudónimos y edad de las mujeres entrevistadas. En segundo lugar, la inestabilidad inherente a las estancias en el centro de acogida dificulta el seguimiento estable de casos (el tiempo de permanencia de cada mujer es incierto) y mucho más el trabajo de campo en entornos relacionales fuera de la institución.

Estudios futuros pueden extender este análisis a otros colectivos étnicos y/o a centros de acogida de otras comunidades autónomas, además de desarrollar algunos factores asociados a las condiciones de vulnerabilidad mencionadas, como por ejemplo la influencia de prejuicios etnocéntricos o miradas alterófobas en las adhesiones a ciertos referentes étnicos, o las transformaciones en las redes de apoyo tras las experiencias de acogida en centros de protección durante el periodo de crianza.

\section{Notas}

1. Estos trabajos de campo se han llevado a cabo en el seno del proyecto Crianza, desamparo $y$ vulnerabilidad sociocultural. Análisis situacional y propuestas de intervención (CSO2017-83101-C2-1-R), codirigido por Jorge Grau y Anna Piella, y financiado por el Ministerio de Ciencia, Innovación y Universidades.

2. En este sentido, serían necesarios más estudios también sobre procesos de reagrupación familiar en destino. Según datos del Portal de la Transparencia de la Administración General del Estado, en el periodo 2000-2020 las solicitudes de reagrupamiento familiar de ciudadanos senegaleses fueron 8.745 de las que fueron concedidas 8.208 (93.85\%), mientras que las solicitudes de reagrupamiento familiar de ciudadanos gambianos fueron 2.439 de las que fueron concedidas $1.978(81.09 \%)$ (comunicación personal por correo electrónico a requerimiento de información por parte de Beatriz García, 20 de julio de 2020). 


\section{Bibliografía}

Agènce Nationale de la Statistique et de la Démographie (ANSD)

2014 Rapport definitif RPGHAE, 2013. Dakar, ANSD.

Aixelà, Yolanda

2006 "Islam and women; Europe and Islam", Transfer: Journal of Contemporary Culture, n 1: 69-77.

2013 "Equatorial Guinean women's roles after migration to Spain: Conflicts between women's androcentric socialization in Equatorial Guinea and their experiences after migration", Urban Anthropology, $\mathrm{n}^{\circ}$ 42: 1-55.

2020 "The presence of the colonial past: Equatorial Guinean women in Spain", Itinerario, $\mathrm{n}^{\circ}$ 44: 140-158. https://doi.org/10.1017/S016511532000008X.

Alberdi, Inés (y Natalia Matas)

2002 La violencia doméstica. Informe sobre los malos tratos a mujeres en España. Barcelona, Fundación La Caixa.

Arnoso, Maitane (y otros)

2012 "Mujer inmigrante y violencia de género: factores de vulnerabilidad y protección social", Migraciones (Madrid), $\mathrm{n}^{\circ}$ 32: 169-200.

Consejo Económico y Social

2019 La inmigración en España. Efectos y oportunidades. Madrid, CES.

http://www.ces.es/documents/10180/5209150/Inf0219.pdf.

Diop, Fatou

2015 Rapport technique final projet "Violences basées sur le Genre au Sénégal: la prévention comme alternative aux périls de sécurité et de Justice (2012-2015). Universite Gaston Gerger de Saint-Louis, Senegal, Groupe d'Etudes et de Recherches Genre et Societes (GESTES).

Garnweidner-Holme, Lisa Maria (y otros)

2017 "Talking about intimate partner violence in multi-cultural antenatal care: A qualitative study of pregnant women's advice for better communication in South-East Norway", BMC Pregnancy and Childbirth, $\mathrm{n}^{\circ}$ 17: 1-10. https://doi.org/10.1186/s12884-017-1308-6.

Generalitat de Catalunya

2011 La població de nacionalitat senegalesa o gambiana a Catalunya. Barcelona, Generalitat de Catalunya, Direcció General per a la Immigració.

https://treballiaferssocials.gencat.cat/web/.content/03ambits_tematics/05immigracio _

refugi/dades_immigracio/immigracio_en_zifres/La__immigracio_en_xifres_10-SeneGambia.pdf.

Goldberg, Alejandro

2015 Procesos de socialización/educación de hijos e hijas de familias migrantes senegalesas residentes en Cataluña: un abordaje antropológico, Barcelona, Col-lecció de materials per a la intervenció sòcioeducativa en contextos multiculturals (CON-ciutadania INTER-cultural).

González-Ferrera, Amparo (y otros)

2012 "Child-parent separations among Senegalese migrants to Europe: migration strategies or cultural arrangements?", Annals of the American Academy of Political and Social Science, $\mathrm{n}^{\circ}$ 643, vol. 1: 106-133. https://doi.org/10.1177\%2F0002716212444846.

Houinato, Maxime

2012 La situation de violences faites aux femmes: le mode de reponse et soutien aux survivantes dans les régions de Dakar, Diourbel, Fatick, Kaffrine, Kaolack, Louga, Saint-Louis et Thiès. Dakar, ONU FEMMES.

\section{IDESCAT}

2020 Padró municipal d'habitants. Població estrangera 2019. Barcelona, Institut d'Estadística de Catalunya.https://govern.cat/govern/docs/2020/02/26/09/19/d946b8a1-5216-4e91-

b121-6b9cb7e48deb.pdf.

INE 
2021 Estadística de violencia doméstica y violencia de género (EVDVG). Año 2020. Madrid, Instituto Nacional de Estadística.

Jabardo, Mercedes

2006 Senegaleses en España. Conexiones entre origen y destino. Madrid, Ministerio de Trabajo y Asuntos Sociales.

Jabardo, Mercedes (y Beatriz Ródenas)

2017 "Más allá de las dicotomías. Un análisis de la actividad del trenzado en la diáspora senegalesa desde el feminismo negro", RES. Revista Española de Sociología, vol. 26, n 3: 373-384. https://doi.org /10.22325/fes/res.2017.29.

Jabbi, Alhaji (y otros)

2020 "Prevalence and factors associated with intimate partner violence against women in The Gambia: a population-based analysis", Women and Health, $\mathrm{n}^{\circ}$ 60: 912-928.

https://doi.org/10.1080/03630242.2020.1767264.

Jiménez-Lasserrotte, María del Mar (y otros)

2020 "Understanding violence against women irregular migrants who arrive in Spain in small boats", Healthcare (Suiza), no 8: 1-13. https://doi.org/10.3390/healthcare8030299.

Kaplan, Adriana

1998 De Senegambia a Cataluña. Procesos de aculturación e integración social. Barcelona, Fundación La Caixa.

Kringelbach, Hèléne

2016 "Marrying Out" for love: women's narratives of polygyny and alternative marriage choices in contemporary Senegal", African Studies Review, n 59, vol. 1: 155-174. DOI: 10.1017/asr.2016.7

Leye, Mamadou (y otros)

2017 "Epidemiological and Clinical Aspects of Domestic Violence in Senegal". Health, n 9: 1404-1415. https://doi.org/10.4236/health.2017.910103.

London, Scott

1999 Family law, marital disputing and domestic violence in post-colonial Senegal, West Africa. Tesis doctoral, The University of Arizona. https://repository.arizona.edu/handle/10150/284052.

Menjivar, Cecilia (y Olivia Salcido)

2002 "Immigrant women and domestic violence: common experiences in different countries", Gender and Society, vol. 16, nº 6: 898-920. https://doi.org/10.1177\%2F089124302237894.

Moriana, Gabriela

2018 "La violencia de género en las historias de vida de las mujeres inmigrantes", Aposta, $\mathrm{n}^{\circ} 78$. https://mobiroderic.uv.es/handle/10550/67804.

ONU Mujeres

2021 Tipos de violencia contra las mujeres y las niñas, UNWOMEN.ORG.

https://www.unwomen.org/es/what-we-do/ending-violence-against-women/fags/types-of-violence.

Plaza Aleu, Montserrat

2012 Maternalització $i$ violència masclista. Una anàlisi des de la perspectiva de gènere. Tesis doctoral. Departament de Psicologia Social, Universitat Autònoma de Barcelona.

https://ddd.uab.cat/pub/tesis/2013/hdl_10803

Rodríguez-García, Dan

2006 "Mixed Marriages and Transnational Families in the Intercultural Context: A Case Study of AfricanSpanish Couples in Catalonia", Journal of Ethnic and Migration Studies, $\mathrm{n}^{\circ}$ 32, vol. 3: 403-433, DOI: 10.1080/13691830600555186.

Rodríguez-Martínez, Pilar (y Cristina Cuenca-Piqueras)

2019 "Interactions between direct and structural violence in sexual harassment against Spanish and unauthorized migrant women", Archives of Sexual Behavior, $\mathrm{n}^{\circ} 48:$ 577-588. 
Salazar, Rhacel

2010 "Transnational mothering: a source of gender conflicts in the family", North Carolina Law review, $\mathrm{n}^{\circ}$ 88: 1825-1855. http://scholarship.law.unc.edu/nclr/vol88/iss5/13.

Sorribas, Elena (y Jorge Gracia)

2004 La problemática específica de las mujeres inmigrantes en procesos de violencia familiar de género. Segundas Jornadas sobre violencia familiar, Universidad de Zaragoza.

http://www.unizar.es/sociologia_juridica/jornadas/comunic/viogeneroinmi.pdf.

Spindler, George

1993 "La transmisión de la cultura", en Honorio Velasco y otros (ed.), Lecturas de antropología para educadores: el ámbito de la antropología de la educación y de la etnografía escolar. Madrid, Trotta: 205-242.

The Gambia Bureau of Statistics (GBOS) (y ICF International)

2014 The Gambia Demographic and Health Survey 2013 (DMHS) Banjul, The Gambia.

https://dhsprogram.com/pubs/pdf/FR289/FR289.pdf.

Vives, Luna (e Iria Vázquez)

2017 "Senegalese migration to Spain: transnational mothering practices", Journal of Ethnic and Migration Studies, n 43, vol. 3: 495-512. https://doi.org/10.1080/1369183X.2016.1186531. 